\title{
Influence of Packaging and Stability Test Assessment of an Anti-aging Cosmetic Cream
}

\author{
ANCA MARIA JUNCAN*, LUCA LIVIU RUS \\ Lucian Blaga University, Faculty of Medicine, Preclinical Department, 2A Lucian Blaga Str., 550169, Sibiu, Romania
}

\begin{abstract}
The aim of this study was the development and formulating of a cosmetic product and the assessment of compatibility tests performed on the product, transfered to the cosmetic jar. Sample of cosmetic cream were stored using $50 \mathrm{~mL}$ PP (Polypropylene) plastic containers. The developed cosmetic formulation was monitored under accelerated stability studies. Accelerated stability tests were performed over a period of 30 days while maintaining the productat 4,20 and $40^{\circ} \mathrm{C}$. Quality control initial, and after initiating the accelerated stability test was performed for the developed cosmetic formulation.
\end{abstract}

Keywords: cosmetic product, packaging, functionality, stability test

Currently, cosmetics are considered to be one of the essential commodities of life. Cosmetics are defined asa an item intended to be rubbed, poured, sprinkled, sprayed on, introduced into or applied to the human body or any part thereof for cleasing, protecting, beautifying promoting attractiveness or altering the appearance. Cosmetics are commercially available products, that are used to improve the appearance of the skin [1, 2].

There are several types of packaging materials available and suitable for a variety of cosmetic products. Materials used commonly are glass, metals, plastics, etc. Nowaday, one can easily find a vaste range of beauty products to choose from ranging from white cosmetics, i.e. facial creams and body care products containers used are jars and pots for body lotions, face cream, lip balm powders etc. peelings, color cosmetics e.g. lipsticks, mascara, nail polishes, eye shadow, foundation, perfumes, etc. The containers used are large sticks for lipsticks, compacts for foundations, vials generally for lip gloss and mascara, tubes for eye creams. High-end products are usually seen in glass containers, e.g. perfume. The material, shape, color and durability of the packaging plays an important role when it comes to marketing the cosmetic products. Cosmetic packaging is the most important part of the branding [3, 4].

Packaging is the process of designing and producing the container or wrapper which stores, protects, identifies and promotes a product. It can include three types of packaging: a) primary, b) secondary and c) distribution (shipping) package [5].

The container, also known as primary package or inner package, could be defined as the packaging designed to come into direct contact with the cosmetic product [6].

When creating a new product any company must establish the packaging concept which defines how the package of the product should look like and what it should do for the product. They have to decide whether the package only protects the product or it will be used as a promotion tool. All the elements of the package (i.e. size, shape, materials, colour, brand mark) should work together to support the product's position and marketing strategy and must be discussed [5].

Packaging plays a great role in the branding of cosmetic products. The overall look of a cosmetic product is one of the most important determinants of its market appeal, besides its quality. Cosmetics packaging should be easy to brand; it should allow the name of the product, the brand, and other necessary information like composition, usage instructions, and warnings to be printed as required. The container should be designed in such a way that the product is easy to come out for use. Other than easy to use, another important element of cosmetics packaging is it's pilfer resitence. Almost all cosmetic containers have a seal or a component which is broken when they are opened for the first time. This ensures that the product is brand new and hasn't been tampered. The four main aspects that matter for the selection of a cosmetics container are the type of container, it's functionality and the protection of the products. The advantages and disadvantages of some container are listed in table 1 [3].

Plastic cosmetic containers are used in the cosmetic industry because of their sturdy body and affordable price. They are available in a variety of shapes and sizes to suit the specific requirements of the manufacturer. These containers are also available in differnet types of plastic compositions. The most common type of plastic used for cosmetic containers is PP (Polypropylene) plastics. However these can also come in a more affordable PET (Polyethylene terephthalate) plastic or a higher-end acrylic plastic. Acrylic plastic is usually clear, and resembles glas. This type pf material has an advantage over glass as is not prone to breakage. PP plastic is more affordable than acrylic and it is usually not clear $[3,7]$.

Plastic packaging has a wide variety of applications in the food and consumer goods industry due to its versatile features and low cost. Some companies involved in the manufacturing and distribution of cosmetics have started incorporating environment-friendly materials in the packaging [8].

The ideal packaging materials are obtained from renewable biological resources, usually called biopolymers, with excellent mechanical and barrier properties and being biodegradable at the end of their life [9].

Also colorants, for bioplastics are being widely investigated. Of particular interest are colorants that have no adverse effect on health or the environment [10].

In the Regulation 1223/2009, evaluation of packaging has become mandatory to assure cosmetic product safety 
Table 1

ADVANTAGES AND DISADVANTAGES OF COSMETIC CONTAINERS

\begin{tabular}{|c|c|c|c|}
\hline Container type & Purpose & Advantages & Disadvantages \\
\hline $\begin{array}{c}\text { Jars (plastic, glass, } \\
\text { ceramic) }\end{array}$ & $\begin{array}{c}\text { Personal care } \\
\text { - semi-solid W/O and } \mathrm{O} / \mathrm{W} \\
\text { emulsions } \\
\text { - hydrogels }\end{array}$ & $\begin{array}{l}\text { - easy use, using spatula } \\
\text { or cotton pads } \\
\text { - decorative }\end{array}$ & $\begin{array}{c}\text { - unhygienic- contamination during } \\
\text { use }\end{array}$ \\
\hline $\begin{array}{c}\text { Tubes (plastic, } \\
\text { composite materials, } \\
\text { aluminium) }\end{array}$ & $\begin{array}{c}\text { Personal care } \\
\text { - semi-solid W/O and O/W } \\
\text { emulsions } \\
\text { - oleogels } \\
\text { - hydrogels }\end{array}$ & - aluminium & - non-decorative \\
\hline $\begin{array}{l}\text { Bottles (plastics, } \\
\text { glass, ceramics, } \\
\text { aluminium) }\end{array}$ & $\begin{array}{c}\text { Personal care } \\
\text { - professional use } \\
\text { - W/O and O/W emulsions }\end{array}$ & $\begin{array}{l}\text { - variable synthetic } \\
\text { material } \\
\text { - frothing caps } \\
\text { - pump head }\end{array}$ & $\begin{array}{l}\text { - requires high microbiological } \\
\text { stability } \\
\text {-radiation cand penetrate through } \\
\text { transparent bottles, hence they are } \\
\text { not appropriate for sensitive } \\
\text { components }\end{array}$ \\
\hline $\begin{array}{c}\text { Dispensers (plastic, } \\
\text { glass) }\end{array}$ & $\begin{array}{c}\text { Personal care } \\
\text { - semisolid emulsions } \\
\text { - hydrogels } \\
\text { - oils, liquid wax }\end{array}$ & $\begin{array}{l}\text { - hygienic- airless } \\
\text { dispensers }\end{array}$ & $\begin{array}{l}\text {-radiation cand penetrate through } \\
\text { transparent bottles, hence they are } \\
\text { not appropriate for sensitive } \\
\text { components }\end{array}$ \\
\hline Sachets (plastic foil) & $\begin{array}{l}\text { Personal care } \\
\text { - professional use } \\
\text { - free samples } \\
\text { - beauty mask }\end{array}$ & $\begin{array}{c}\text { - hygienic } \\
\text { - single use } \\
\text { - promotion material }\end{array}$ & $\begin{array}{c}\text { - packaging waste } \\
\text { - opened products have to be used } \\
\text { immediately }\end{array}$ \\
\hline
\end{tabular}

[11]. Article 17 states that the non-intended presence of a small quantity (traces) of a prohibited substance (prohibited in cosmetic products according to Annex II of the regulation on cosmetic products), stemming from (...) migration from packaging, which is technically unavoidable in good manufacturing practice, shall be permitted provided that such presence is in conformity with Article 3". Article 3 of the regulation on cosmetic products states that a cosmetic product made available on the market shall be safe for human health when used under normal or reasonably foreseeable conditions of use [12].

The characteristics of the packaging materials that are in direct contact with the product must be assessed, as they may have an impact on the finished product's safety. Some substances may migrate from the container to the product. Compatibility of the product with its container may be assessed as a part of the stability test (see section above). In addition to providing information on the potential migration of substances, compatibility testing will provide an indication of the (lack of) interactions between the product and the container and will assess possible deterioration of the product in contact with the packaging, which may also be influenced by the external environment. Correct assessment of the substance migration risk will help select the appropriate packaging material (e.g. for light-sensitive formulas) and storage conditions (which can be then indicated on the product label) [13].

Compatibility tests should be performed on the product, once transferred to the final container. The containercontent relationship should be explored for all the packaging materials, as the final quality of the goods is always the result of a delicate balance between these two components. Simple experimental design, in order to minimize the number of trials, was employed. Polyethylene containers were filled with standard formulations and submitted to different degradation tests (photostability test and accelerated stability test) to mimic stress conditions that products can meet during their shelf life, according to European guidelines for stability tests on cosmetic products [11].

Personal care packaging market is primarily driven by strong demand for personal care products. Strong economical growth and changing lifestyle coupled with increasing disposable income is key market driver of personal care products in emerging economies. Increasing usage of skin and hair care products owing to awareness regarding hygiene and beauty is expected to fuel personal care packaging market growth over the next few years. However, increasingly stringent regulations for personal care packaging can adversely affect the growth of this industry to some extent. Figure 1. expresses an overview

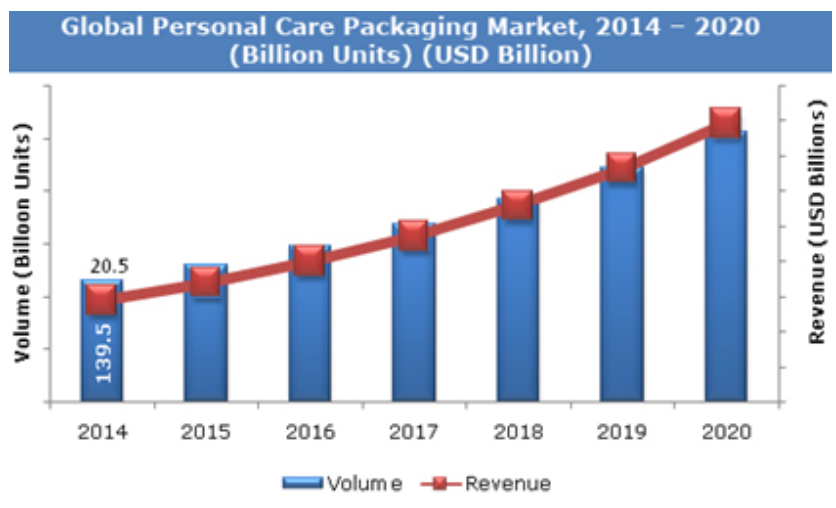

Fig. 1. The Global Personal Care Packaging Market (2014-2020) 


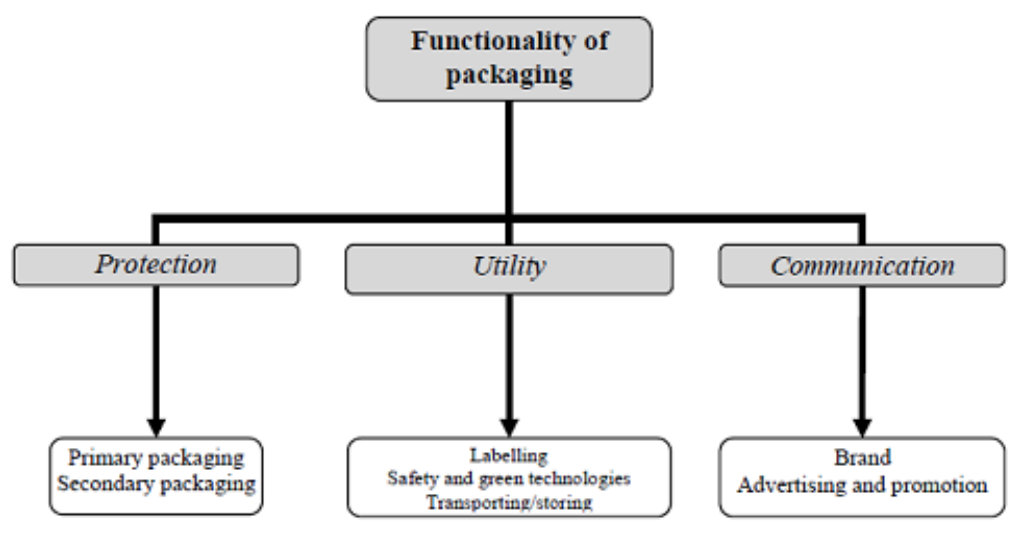

Fig. 2. Structured Features of Functionality of Product Packaging

of the global personal care packaging market from 20014 and the forcast to 2020 [14].

In such a competitive market like cosmetics, product packaging and aesthetics takes a leading role in the marketing and interaction between brand and consumer processes [15].

The cosmetics industry requires packaging materials that provide efficient barriers, preserve product effectively and increase the life of cosmetic products. Packaging helps consumer to understand the contents of the product and usage. Consumer's packaging choice is generally an economic decision made by comparing costs and benefits ratio. How ever, packaging has not only functional utilities. As a marketing tool, packaging has some important roles (fig. 2) [16].

\section{Experimental part}

\section{Materials and methods}

Preparation of the anti-aging cosmetic formulation

The ingredients used in the anti-aging cream formulation were: deionised water, isoamyl laurate, octyl methoxycinnamate, glyceryl stearate citrate, cetearyl alcohol, glyceryl caprylate (Dr. Straetmans $\mathrm{GmbH}$.), squalane (Sophim, France), Camelia sinensis extract (Symrise AG, Holzminden, Germany), glycerin, cyclopentasiloxane, cyclohexasiloxane, butyl methoxydibenzoylmethane, Butyrospermum Parkii (Dr. Straetmans GmbH.), hydrolyzed collagen (BASF SRL, Bucuresti, Romania), dimethicone, caprylyl glycol, glyceryl caprylate, phenylpropanol, tocopheryl acetate, Helianthus Annuus Seed Oil, xanthan gum (Biesterfeld Spezialchemie Romania S.R.L.), parfum (CPL Aromas, Brixworth, UK), sodium polyacrylate (ISP, Köln, Germany), sodium phytate (Dr. Straetmans GmbH.). Figure 3. shows the composition of the developed anti-aging cream.

Manufacturing procedure: Phase $\mathrm{A}$ (aquaous Phase) was heated up to $78^{\circ} \mathrm{C}$ and Sodium Polyacrylate and xanthan gum were dispersed. Phase $B$ was heated up to $78^{\circ} \mathrm{C}$. Phase $B$ was emulsyfied into Phase A under stirring and homogenized for 1-2 min., using an ultra turrax. Medium stirring was performed for cooling down. Phase $C$ (Camelia sinensis extract and hydrolyzed collagen) and Phase D (parfum) were added below $40^{\circ} \mathrm{C}$ and cooling down was performed under stirring.

\section{Packaging of the cosmetic product}

Sample of cosmetic cream were stored using $50 \mathrm{~mL}$ PP (Polypropylene) plastic containers. Tehnical specification of the cosmetic jar and cap are presented in table 2 , respectively (table 3 ). Table 4 and figure 4 . show the tehnical specification of the cosmetic jar and cap ensemble, respectively the tehnical scheme of the cosmetic jar and cap ensamble.

\section{Accelerated Stability Test and Relevant Physico-chemical Characteristics \\ The purpose of stability testing cosmetic products is to ensure that a new or modified product meets the intended physical, chemical and microbiological quality standards}

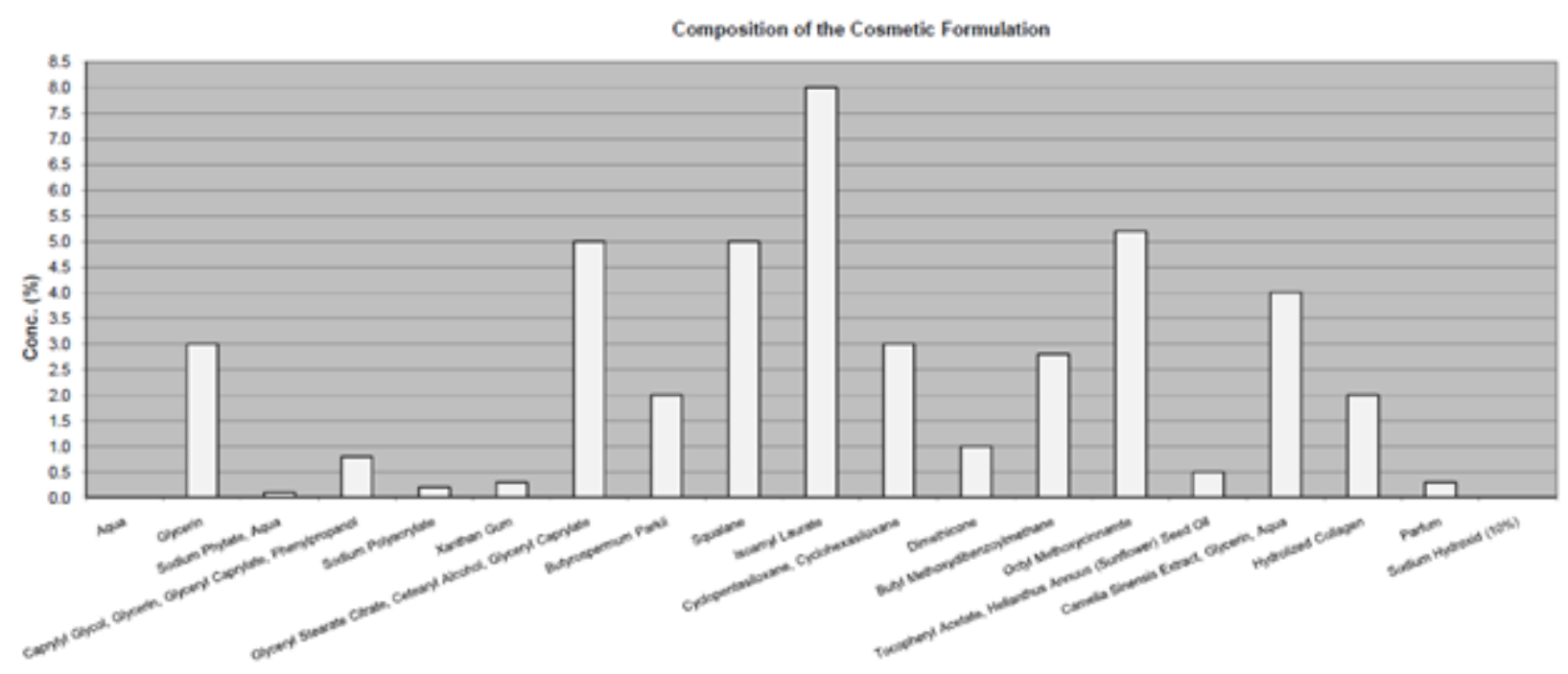

Ingredients 


\begin{tabular}{|c|c|c|}
\hline \multicolumn{2}{|c|}{$\begin{array}{l}\text { Tehnical Specification } \\
\text { Cosmetic jar } 50 \mathrm{~mL}\end{array}$} & \multirow{15}{*}{$\begin{array}{c}\text { Table } 2 \\
\text { TEHNICAL } \\
\text { SPECIFICATION OF } \\
\text { THE COSMETIC JAR }\end{array}$} \\
\hline \multicolumn{2}{|l|}{ Cosmetic jar } & \\
\hline High & $42.3 \pm 0.5$ & \\
\hline Weight & $22 \pm 0.5$ & \\
\hline \multicolumn{2}{|l|}{ Interior } & \\
\hline Raw material & PPHP500 & \\
\hline Colour & White & \\
\hline \multicolumn{2}{|l|}{ Dimensions } & \\
\hline Inner diameter & $46 \pm 0.2$ & \\
\hline Thread diameter & $54.6 \pm 0.2$ & \\
\hline Thickness & $3.1 \pm 0.1$ & \\
\hline \multicolumn{2}{|l|}{ Exterior } & \\
\hline Raw material & PPHP500 & \\
\hline Colour & white & \\
\hline High & $30 \pm 0.2$ & \\
\hline
\end{tabular}

as well as functionality and aesthetics when stored under appropriate conditions. Whether conducted in real time or under accelerated conditions, tests should be done in order to assure:

-stability and physical integrity of cosmetic products under appropriate conditions of storage, transportand use,

- chemical stability,

- microbiological stability,

-the compatibility between the contents and the container.

Because of the wide variety of cosmetic products and their inherent complexity, standard stability tests cannot be prescribed. Manufacturers, who have an intimate knowledge of their products and packages, require the flexibility to modify testing protocols and to build a sound scientific basis for assessing product stability. Thus, specific tests may be developed in order to predict possible evolutions of the product, to address new/unusual technologies, or to be adapted to products having extended shelf lives. Accelerated test conditions are internationally recognized as appropriately predicting product shelf life in many industries.

Stability testing should include packaging which is made of exactly the same material(s) and is as similar as possible in all other respects to the package in which the product will be marketed.

When designing a stability test protocol, it is important to bear in mind that as products age, their properties may change. Because of this fact, stability testing may need to involve testing of properties beyond those which will be evaluated for initial release testing [17].

The developed cosmetic formulation was monitored under accelerated stability studies. Accelerated stability tests were performed over a period of 30 days while maintaining the product at 4,20 and $40^{\circ} \mathrm{C}$.

Quality control initial, and after performing the accelerated stability test consisted of the following determinations:

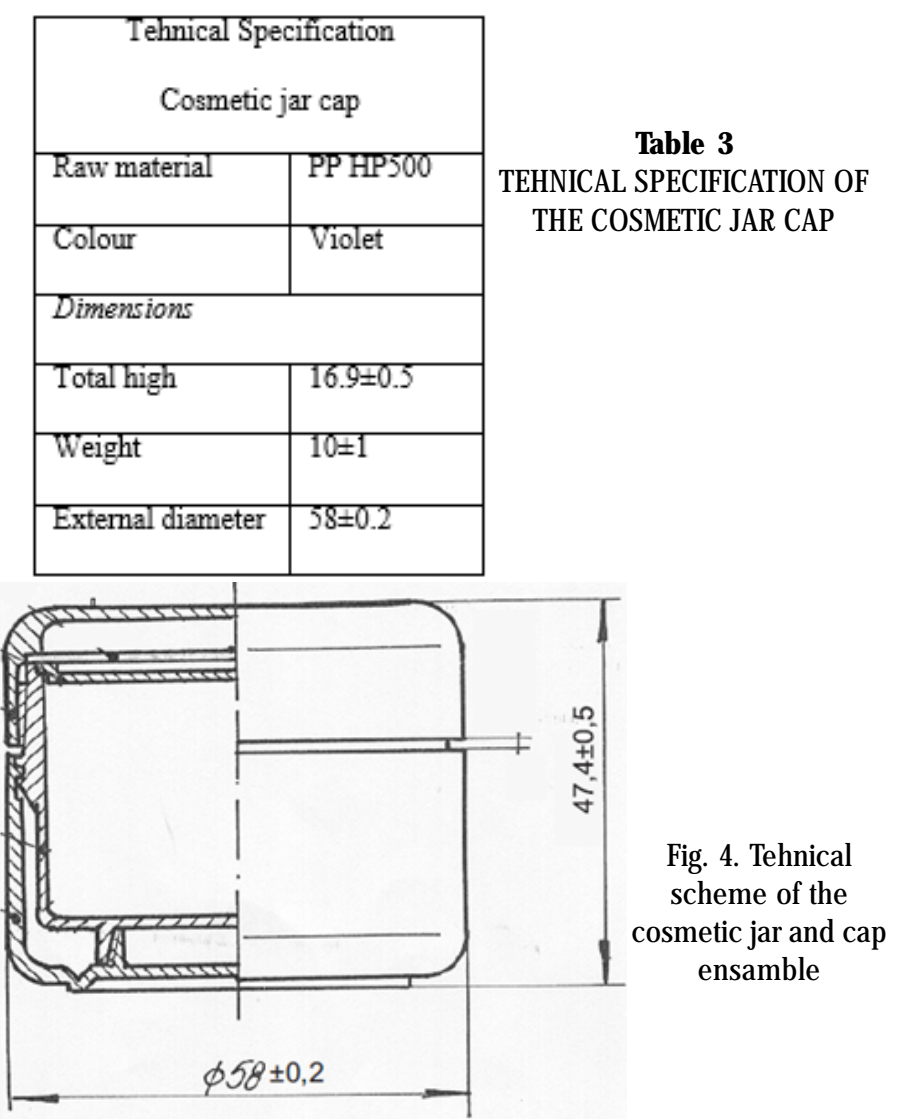

- the appearance, color and odor were tested organoleptically;

- $\mathrm{pH}$ determination was performed using a $\mathrm{pH}$ meter (Mettler Toledo (Schwerzenbach, Switzerland));

- viscosity was performed using a HAAKE Viscotester VT550 (spindle $R=6$, shear rate $D=5 \mathrm{~s}^{-1}$, temperature $\mathrm{T}=20^{\circ} \mathrm{C}$ ).

\section{Results and discussions}

A cosmetic cream was developed and accelerated stability testing was performed including packaging. There are some advantages of plastic containers like low cost, light in weight, durable, odorless and inert to most chemicals, that are incorporeted in a cosmetic product, and able to retain their shape throughout their use. Contrariwise, plastic appear to have certain disadvantage like interaction, adsorbtion lightness and hence poor physical stability; stress cracking is a phenomen related to low density polythene and certain stress cracking agents such as wetting agents, detergents and some volatile oils can deteriorate the plastic jar.

Accelerated stability studies performed over a period of 30 days, while maintaining the product at 4,20 and $40^{\circ} \mathrm{C}$, showed that the formulated and studied cosmetic product is stable, and there was no deterioration of the plastic jar.

Quality control of the developed cosmetic cream revealed: achieving an acceptable cosmetic preparation with elegant appearance and appropriate physicochemical and pharmacotechnical (pH, viscosity) characteristics. The determination results initial, and after 30 days are shown in table 4.

\section{Conclusions}

There is a clear association between packaging of a product, where glass, metal and plastic packaging are associated with the generic aspect of cosmetics. The packaging material used has to be in good appearance, as well it should be compatible with the content. Acording to 


\begin{tabular}{|c|l|l|}
\hline \multicolumn{2}{|c|}{$\begin{array}{c}\text { Admissibility conditions } \\
\text { (initial) }\end{array}$} & $\begin{array}{c}\text { Admissibility conditions } \\
\text { (30 days) }\end{array}$ \\
\hline Appearance & homogeneous cream & concordant \\
\hline Odor & characteristic odor, perfumed & concordant \\
\hline Color & White/beige & concordant \\
\hline pH & $5.5-6.0$ & $5.5-6.0$ \\
\hline Viscosity & $35.000 \mathrm{mPas}$ & $45.000 \mathrm{mPas}$ \\
\hline
\end{tabular}

Table 4

PHYSISCO-CHEMICAL CHARACTERISTICS OF THE DEVELOPED CREAM the needs of cosmetics, materials for containers cand be selected and used.

The accelerated stability studies performed in this study for a developed cosmetic formulation, showed that the formulated and studied cosmetic product is stable, the cosmetic product is compatible with the PP cosmetic jar and there was no deterioration of the plastic jar. Quality control of the developed cosmetic cream revealed an acceptable cosmetic preparation with elegantappearance and appropriate physico-chemical and pharmacotechnical ( $p H$, viscosity) characteristics initial, and after 30 days.

Acknowledgement: Special thanks are extended to cosmetic ingredients distributors and cosmetic packaging manufacturer for providing raw materials, respectively PP cosmetic jars used for the development, formulation and packaging of the moisturizing cosmetic product.

\section{References}

1.MURALIDHAR, P., NAGENDRA, P., SWETHA, B., BHARGAV, E., Int. Res. J. Pharm., 7,12, 2016, p. 1.

2. JUNCAN, A. M., HODISAN, T., Rev. Chim. (Bucharest), 62, no. 4, 2011, p. 415.

3.SHIVSHARAN, U. S., RAUT, E. S., SHAIKH, Z. M., JPSI, 3, 4, 2014, p. 286.

4.RITNAMKAM, S., SAHACHAISAEREE, N., Procedia. Soc. Behav. Sci., 50, 2012, p. 1018.
5.GRUNDEY, D., Econ. Sociol., 3, 1, 2010, p. 87. 6.GOMEZ-BERRADA, M. P. , FICHEUX, A. S., GALONNIER, M., ROLFO, J. E., RIELLAND, A., GUILLOU, S., DE JAVEL, D., ROUDOT, A. C., FERRET, P. J., Food. Chem. Toxicol., 109, 2017, p. 230.

7.YANG, Y., LI, Y., Adv. Mat. Res., 690-693, 2013, p. 3410.

8.DAYAN, N., KROMIDAS, L., Formulating, Packaging, and Marketing of Cosmetic Products, John Wiley \& Sons, Inc., Hoboken, New Jersey, 2011, p. 411- 418.

9.RAPA, M., DARIE NITA, R. N., VASILE, C., Mat. Plast., 54, no. 1, 2017, p. 73.

10.IGNAT, G., COLIBABA, C., COSTULEANU, C. L., BALAN, A., ROTARU, L., SANDU, I. C. A., Mat. Plast., 53, no. 3, 2016, p. 367.

11.BRIASCO, B., CAPRA, P., COZZI, A. C., MANNUCCI, B., PERUGINI, P., Cosmetics, 3, 32, 2016, p. 2

12.KUHN, A., COSSMA, 5, 2014, p. 26.

13.EIXARCH, H., ANDREW, D., Personal Care Magazine, 4, 2018, p. 13. 14.*** http://www.marketresearchstore.com/news/global-personalcare-packaging-market-set-for-rapid-110 (accesed on 25.05.2018)

15.SILAYOI, P., SPEECE, M., Br. Food. J., 106, 8, 2004, p. 607. 16.PETERS-TEXERIA, A., BADRIE, N., Int. J. Consum. Stud., 29, 6, 2005, p. 508.

17.*** The Cosmetic, Toiletry, and Fragrance Association (COLIPA), CTFA, Guidelines on stability testing of cosmetic products, 3, 2004, p. $1-8$

Manuscript received: 21.06 .2018 